\title{
TRADUÇÃO DE MARCADORES CULTURAIS EM TEXTOS TÉCNICOS: A FUNÇÃO DO TEXTO E O PAPEL DO TRADUTOR NO CONTATO ENTRE LÍNGUAS E CULTURAS ${ }^{1}$
}

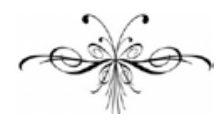

\section{Clara Peron Guedes}

\author{
ISABELLA MOZZILLO
}

\begin{abstract}
Resumo: A tradução de textos técnicos vem ganhando espaço devido aos avanços tecnológicos e às expansões comerciais geradas pela globalização. Entretanto, o papel do tradutor que a realiza nem sempre recebe a merecida atenção. Na área acadêmica há certa carência em relação à teoria específica sobre a tradução de textos de especialidade. Este trabalho pretende contribuir para saná-la ao propor a atividade tradutória como espaço privilegiado para o contato entre línguas e culturas. Para tanto, investiga-se a tradução de aspectos culturais de manuais de instruções nos quais fica evidente a importância de se considerar os marcadores culturais nesse tipo de tradução.
\end{abstract}

Palavras-chave: Tradução técnica. Marcadores culturais. Tradutor. Contato entre línguas. Contato entre culturas.

\begin{abstract}
The translation of technical texts has been increasing due to technological advances and to the commercial expansion produced by globalization. However, the translator's role in this activity does not always receive its deserved attention. In academia there is a scarcity of specific theories focused on the translation of technical texts. This work aims at contributing to fill this gap by proposing that translation should be viewed as privileged loci for the contact between languages and cultures. With this purpose, it investigates the translation of cultural aspects in instruction manuals in which the importance of considering cultural markers in this kind of translation becomes evident.
\end{abstract}

Keywords: Technical translation. Cultural markers. Translator. Language contact. Cultural contact.

${ }^{1}$ Artigo escrito a partir do trabalho de conclusão do curso de especialização em Tradução - Inglês, da Universidade Gama Filho, realizado sob a orientação da professora Simone Vieira Resende. 
$\mathrm{T}$ extos técnicos, muitos deles traduzidos, são uma grande parcela das leituras diárias. Entretanto, parece haver uma concepção equivocada de que são rápidos e fáceis de traduzir. Segundo alguns creem, para tanto seria necessário apenas dominar a terminologia de uma determinada área. Além disso, são considerados como de menor valor estilístico, sem muita variação lexical e, por isso, traduzíveis com equivalência total do conteúdo temático. Porém, segundo Azenha (1996, p. 141):

a experiência de trabalho com a tradução de textos técnicos nos mostra que os tipos textuais são instáveis, que os textos são formas híbridas, que todos os textos estão sujeitos a um número elevadíssimo de variáveis e que a terminologia, longe de ser algo estático, é dinâmica e reconhece sua dificuldade em controlar a subjetividade no tratamento de seu objeto, a linguagem.

Assim, por mais específico e fixo que possa parecer à primeira vista, todo texto tem suas "marcas culturais" - elementos que distinguem uma língua fonte de uma língua alvo -, tais como expressões idiomáticas, metáforas, jogos de palavras, referências de humor, sistema de medição, códigos e regimentos, que são peculiares à determinada cultura. Segundo Resende (2011, p. 119), um “marcador cultural” é a materialização do que chamamos de condicionante cultural, ou seja, os fatores externos existentes numa cultura que influenciam a produção de um texto. Esses se apresentam como nós, isto é, momentos nos quais o tradutor precisa se posicionar e fazer escolhas, sejam elas estrangeirizantes ou domesticantes, de acordo com as definições de Venuti (1995).

É certo que questões ideológicas e de sigilo tecnológico podem influenciar, ou mesmo serem impostas, nas escolhas lexicais, estratégias e decisões do tradutor. Porém, ele ainda se faz presente, pois essa modalidade de tradução também apresenta questões linguísticas e culturais sobre as quais cabe a ele decidir se são passíveis de intervenção.

As relações linguísticas e sociais inerentes à tradução revelam a atividade tradutória como um espaço privilegiado de contato entre culturas. No momento da tradução, ao menos dois sistemas linguísticos estão explicitamente em contato, bem como as potenciais convenções e questões extratextuais envolvidas na produção e na recepção dos textos fonte e alvo. Ao traduzir, é importante que o tradutor considere as interferências que pode ocorrer devido a essa relação tênue entre códigos sociais e línguas.

O presente trabalho analisa escolhas tradutórias em manuais de instruções de produtos como caixa de som para celular e relógio de pulso. Esses apresentam um vocabulário específico, cuja terminologia possui uma denominação fundamentada em um sistema conceitual determinado, que revelam o funcionamento dos aparelhos. Entretanto, por ser a língua parte integrante da cultura, também estão expostos a variantes culturais, lexicais e sintáticas. Assim, é importante que o tradutor conheça, além da terminologia, tais especificidades, a fim de tornar o texto adequado à função que exercerá perante o público-alvo e na cultura-alvo, evitando estranhezas, ambiguidades, e até problemas de comunicação. 


\section{A função do texto técnico}

O discurso técnico está ligado a uma linguagem especifica, porém, as condições de produção de um texto concreto, isto é, as situações extralinguísticas, são fatores determinantes na identificação do conteúdo nocional e conceitual, na escolha tradutória e no emprego de determinados termos (POLCHLOPEK e AIO, 2009, p. 104). De acordo com Aubert (2001, p. 24), a linguagem de especialidade pode ser entendida como um conjunto de marcas sintáticas, lexicais, estilísticas e discursivas que são tipificadas dentro de um ambiente específico.

Assim, seguindo Aubert, o corpus escolhido para investigação neste artigo pode ser classificado como sendo parte do gênero de textos de especialidades, ou seja, textos técnicos, já que possui marcas linguísticas sintáticas, tais como o uso do imperativo no texto fonte, traduzido como infinitivo no texto alvo; marcas estilísticas, como inversões de frases, ao se comparar textos fonte e alvo; entre outras marcas específicas de textos instrutivos que serão investigadas mais adiante.

Uma das características importantes a ser considerada na tradução de textos técnicos é a função que exerce. A produção de um texto pode ser definida como uma ação, ou seja, como um comportamento intencional com o intuito de transmitir determinada informação a um ou a vários receptores. Nesse sentido, ela é uma interação, uma comunicação com intuito particular (DE BRUM, 2007, s. p.).

A teoria do Skopo de Hans Vermeer (1989) postula que o objetivo e a função da tradução é que determinam as estratégias tradutórias que devem ser empregadas. Defende, pois, o princípio da funcionalidade, deixando a equivalência entre os textos fonte e alvo em segundo plano, e colocando as questões culturais da tradução em posição de destaque, considerando a atividade tradutória como um ato humano e, portanto, carregada de intenções e envolta em contextos socioculturais concretos de produção e recepção.

Assim, o funcionalismo considera a tradução como uma comunicação intercultural em que texto fonte e texto alvo pertencem a sistemas culturais distintos. Desse modo, suas funções devem ser analisadas separadamente e de maneira pragmática. Os receptores dos textos fonte e alvo são determinantes para o escopo da tradução, pois um texto só tem seu sentido completo na recepção (LEAL, 2006, s.p.).

Christiane Nord (1997), que se inspirou nos estudos de Vermeer (1989), apresenta um modelo de análise textual de traduções com o objetivo de guiar o tradutor ao buscar estabelecer a função do texto fonte na cultura fonte para, posteriormente, esclarecer a provável função do texto alvo em sua própria cultura. Dessa maneira, é possível identificar os elementos a serem preservados e aqueles a serem adaptados.

A autora afirma que a tradução tem como objetivo último a comunicação e, nesse contexto, pensa o tradutor como um mediador cultural. Seguindo Vermeer, propõe um modelo funcionalista da tradução, considerando a atividade tradutória como um ato comunicativo. Desse modo, antes de se iniciar uma tradução, é preciso analisar algumas variáveis que têm ligação direta com a função comunicativa do texto.

Fanaya (2009, p. 55), baseada nos estudos de Nord, lista questões que devem ser consideradas ao se analisarem os fatores extratextuais de uma tradução, tais como: quem produz o texto, para quê, para quem, por qual meio, onde, quando e por que razão. Respostas a essas considerações indicariam a função do texto. Também os 
fatores internos devem ser analisados, assim como temática, conteúdo, pressuposições, marcas suprassegmentais, não verbais, estruturas textuais, léxico e sintaxe.

Leal (2006, s. p.) relata que Nord postula a função do texto como uma noção pragmaticamente determinada, cabendo ao tradutor compará-la nos texto fonte e alvo, sem supor que ambos teriam a mesma função por possuírem tipologia idêntica. Essa abordagem se aplica para a análise do corpus selecionado, uma vez que considerar a função comunicativa que os manuais de instruções têm na cultura alvo é de suma importância na produção de uma tradução, pois somente dessa maneira o texto fonte poderá cumprir seu objetivo primeiro: instruir corretamente o usuário.

É relevante, ainda, considerar o contexto cultural no qual a comunicação ocorre, e isso, segundo Nord (apud FANAYA, 2009, p. 56), só se torna possível por meio da intervenção de um agente interpretante, ou seja, o tradutor. Consequentemente, esse profissional possibilita a comunicação entre membros de diferentes culturas.

O tradutor de textos técnicos, portanto, também tem responsabilidade na definição de estratégias e escolhas lexicais que englobam conhecimento linguístico e cultural. Segundo Azenha (1999, p. 147) é preciso redefinir o papel e a tarefa do tradutor técnico que, dentre suas habilidades, além do domínio de códigos, deve ter criatividade, sensibilidade e experiência de tradução no assunto que traduz. O pesquisador afirma que "é possível evidenciar a importância da consideração de aspectos culturais inclusive na tradução de textos técnicos. Sob essa ótica, o texto técnico passa a ser uma estrutura multidimensional” (AZENHA, 1999, p.11).

Nesse sentido, entender a tradução como um espaço de contato entre línguas e culturas pode trazer ganhos ao tradutor, uma vez que ao considerar as possíveis interferências ocasionadas pela relação entre dois sistemas linguísticos e culturais distintos pode fazer opções de tradução mais adequadas, considerando a cultura alvo, sem desprezar as informações linguístico-culturais presentes no texto fonte, afinal "a tradução integra na língua as marcas subjacentes da presença da outra língua com a qual está em contato" (GOROVITZ, 2012, p.81).

\section{Tradução técnica na teoria e na prática}

A tradução técnica é o ato de traduzir textos considerados técnicos, ou de especialidade, tais como manuais de instrução, bulas de remédios, textos acadêmicos, contratos judiciais, entre outros. Embora algumas pessoas acreditem que essa seja uma atividade menor do que a tradução literária, ela é muito importante no cotidiano, principalmente no campo da tecnologia, mas não só.

Grande parte do material com o qual temos contato em nosso dia-a-dia é proveniente de traduções de textos considerados técnicos. Na área tecnológica, muitos são os textos traduzidos de outras línguas que relatam experiências científicas, detalhando suas metodologias e resultados, que são usados como base para experimentos futuros. Além disso, há um grande volume de textos acadêmicos que necessitam de tradução ou versão. Até mesmo informações sobre os ingredientes contidos em alimentos são, muitas vezes, textos traduzidos. 
Todos eles apresentam questões linguísticas e culturais que devem ser analisadas e solucionadas pelo tradutor. Portanto, podemos afirmar, assim como Azenha (1996, p. 138), que entre as traduções técnicas e literárias existem diferenças de grau, mas não de essência, pois:

traduzir um manual não é uma atividade menor que traduzir um poema. Cada um tem seu valor no seu contexto de importância: o manual não é livro de cabeceira, mas o poema não esclarece as dúvidas de um operador de máquinas (AZENHA, 1996, p. 138).

De acordo com a pesquisa de Polchlopeck e Aio (2009), os textos considerados técnicos fazem parte de um dos maiores segmentos do mercado de tradução. Além disso, segundo as autoras, a tradução técnica no Brasil vem se expandindo, devido à globalização e ao avanço tecnológico experimentado pelo país nos últimos anos. Entretanto, a prática da tradução técnica não tem recebido a devida atenção por parte de pesquisadores. Isso é comprovado pelo fato de até hoje não haver uma teoria de análise especifica para os textos técnicos. Assim, grande parte das pesquisas realizadas usa adaptações de teorias voltadas para a análise de textos literários, como por exemplo, as dissertações de Carvalho (2005) e Resende (2011). Esta, em sua investigação, constatou que não foram nem mesmo encontrados registros de normas tradutórias que levem em consideração textos de especialidade" (RESENDE, 2011, p. 22).

Uma possível explicação para tal fato é que em tese a tradução de textos técnicos seria uma atividade simples e rápida, que corresponderia a encontrar os equivalentes na língua alvo de forma quase automática, com o auxílio de ferramentas de gerenciamento de terminologia específica. Assim, a tradução técnica estaria centrada em uma operação de transcodificação sem muito enquadramento cultural. Desse modo, seus problemas estariam fundamentalmente restritos ao plano lexicalterminológico, e o resultado do trabalho do tradutor seria proporcional ao domínio da terminologia envolvida (AZENHA, 1996, p. 141).

Porém, apesar de não permitirem muita variação estilística, os textos técnicos não podem ser rotulados como tendo menor valor em comparação com os literários, pois fazem parte da disseminação do conhecimento de pesquisas científicas e tecnológicas. Além disso, mesmo sendo considerados técnicos, todos os textos exigem sensibilidade e criatividade por parte do tradutor.

Por mais que textos técnicos possam ter equivalentes fixos, esses podem mudar no decorrer do tempo. Assim, acredita-se que seja necessário aos tradutores pensar na linguagem, considerando cada opção, ajustando-a ou adaptando-a à função exercida pelo texto alvo na cultura em que se insere.

Levando em consideração que textos técnicos também são expostos a variantes culturais, linguísticas, estilísticas, lexicais e sintáticas, no manual de instruções de um relógio de pulso analisado como corpus do presente estudo, por exemplo, podemos observar as variações estilístico-culturais no caso das iniciais das palavras em cada subtítulo. No texto fonte, em inglês, todas elas aparecem em caixaalta, já no texto alvo, como manda a regra cultural adotada nas normas para o 
português do Brasil, somente a inicial da primeira palavra está grafada em caixa-alta, enquanto as demais ficam em caixa-baixa.

Por esses motivos, seria importante para 0 tradutor conhecer as especificidades da cultura alvo e do público para o qual uma tradução é destinada, ou seja, a função do texto, de maneira a pensar em suas escolhas tradutórias de forma consciente e considerando todas as possíveis interferências decorrentes do contato íntimo entre línguas e culturas envolvidas no processo tradutório.

\section{A tradução como contato entre línguas e culturas}

A tabela das áreas de conhecimento elaborada pelas associações científicas representativas da grande área de Linguística, Letras e Artes: ABRALIC (Associação Brasileira de Literatura Comparada), ABRALIN (Associação Brasileira de Letras e Linguística), ANPOLL (Associação Nacional de Pesquisa e Pós-graduação em Linguística) e ALAB (Associação de Linguística Aplicada do Brasil), enquadra a tradução na área Linguagens e Interfaces. Nesse sentido, é possível afirmar que a Tradução e a Linguística Aplicada são áreas afins. Assim sendo, podemos considerar a Tradução como relacionada à subárea da Linguística Aplicada denominada Línguas em Contato.

A tradução é uma atividade na qual ao menos duas línguas, culturas e sociedades distintas estão em contato. É o momento em que o “outro” se faz presente, cabendo ao tradutor fazer a mediação entre esse e o leitor, podendo aproximar ou apagar esse outro.

Como afirma Gorovitz (2012, p. 76), a atividade tradutória é vista “como um tipo de contato linguístico, como um momento em que duas línguas se encontram em contato, seja ele apreendido como uma sobreposição, uma alternância, uma mistura, ou ainda uma ampliação”.

Traduzir é um processo que vai para além da simples transposição das palavras de uma língua para outra. Ele envolve uma relação entre línguas que abarca, para além dos critérios linguísticos, fatores pragmáticos, culturais e normativos. Durante o ato tradutório, o profissional gerencia duas línguas, duas culturas, dois códigos que entram em contato em suas escolhas de tradução. De acordo com Gorovitz (2012, p. 76), "podemos considerar que no exato momento da tradução duas línguas em enunciação estão em contato”. Não é possível converter o texto de uma língua para outra sem que haja essa relação de troca semântica e lexical. Ter consciência disso pode ajudar o tradutor em suas escolhas e propiciar melhoria em suas estratégias de tradução.

A não percepção de possíveis interferências geradas pela proximidade ou diferença entre as línguas e as culturas pode resultar em um texto alvo pouco idiomático, ou que cause estranheza no leitor da cultura alvo, o que pode não ser o objetivo da tradução, e em tradução técnica esse efetivamente não é o objetivo, como veremos nos exemplos analisados posteriormente. 


\section{A cultura presente (ou oculta) no texto técnico}

A língua é um organismo vivo e, portanto, em constante transformação. Ela está a todo o momento sofrendo a influência da sociedade e da cultura na qual está inserida. Desse modo, não podemos considerar a tradução de textos técnicos como à margem dessa realidade. A língua e a cultura estão sempre em processo de mudança, e a tradução, em todas as suas faces, deve se adequar a essas alterações, inclusive o âmbito da tradução dos textos técnicos, que não devem tomar suas terminologias de forma estanque, mas devem seguir as modificações histórico-culturais de cada época. Como afirma Azenha (1996, p. 142), “partindo-se das relações fundamentais entre linguagem e cultura, é possível evidenciar a importância da consideração de aspectos culturais na tradução de textos técnicos”.

Podemos ir além das questões linguísticas ao pensarmos na interferência da cultura sobre a tradução, pois de acordo com Resende (2011, p. 25), para que a tradução seja aceita e o papel do tradutor seja cumprido, ele precisa saber as normas operantes em determinada cultura, uma vez que as variações lexicais e o vocabulário técnico podem sofrer alterações de uma cultura para outra.

Além disso, o texto técnico também sofre influências de condicionantes culturais, apresentando marcas culturais textuais. Segundo Resende (2011, p. 51), “uma condicionante cultural é a constelação de fatores externos que influenciam a produção do texto, e as marcas textuais são os registros dessas influências”. Um exemplo de influência da condicionante cultural é o sistema de medição; já a forma como essa condicionante é materializada resulta na marca cultural.

Como as marcas culturais fazem parte de um texto, espera-se que o tradutor faça a transposição delas; nesse processo, estará mediando também a transposição de modos de dizer das comunidades envolvidas. E nesse momento as línguas e culturas em jogo entram em contato de maneira intensa. Isso diz respeito tanto aos níveis lexical e gramatical, como às formas que serão reconhecidas pelo público alvo. Portanto, "toda a ideia de condicionamento cultural e social, ou de pertinência a um grupo ou a uma situação, é fundamental para a reflexão sobre fatores envolvidos no processo tradutório” (POSSAMAI e LEIPNITZ, 2007, p. 2021).

\section{O papel do tradutor técnico}

Há uma concepção errônea e generalizada de que para ser um bom tradutor técnico é preciso apenas dominar o vocabulário específico da área, possuir um bom banco terminológico e dominar as línguas fonte e alvo, como se o processo tradutório se resumisse em encontrar equivalentes de maneira automática, sem considerar o contexto em que o texto foi produzido, bem como seu público alvo.

No entanto, o tradutor de textos de especialidade deveria ter as mesmas habilidades que os tradutores literários, ou seja, dominar o máximo possível as línguas fonte e alvo, saber pesquisar corretamente os termos específicos, e ter sensibilidade e criatividade para solucionar problemas diversos e de outras estirpes. Afinal, ele tem responsabilidade na definição de estratégias que englobam conhecimento linguístico e cultural. A esse respeito, Azenha (1996, p. 146) afirma que: 
a chave para uma atuação mais ou menos eficaz do tradutor parece estar no seu grau de consciência das variáveis que entram em jogo em cada caso e na sua habilidade em controlar tais variáveis com a determinação de objetivos e estratégias claros, realizáveis através do uso otimizado dos instrumentos de apoio disponíveis, (...) capacidade e predisposição do profissional em estabelecer os limites, objetivos e estratégias de cada trabalho que realiza; em suma, uma habilidade em mostrar à instância que lhe encomenda o trabalho seu papel de corresponsável no resultado final.

É muito importante que o profissional se mantenha atualizado e se perceba também como leitor, pois erros na interpretação do texto fonte podem levar a enganos no texto alvo, que podem gerar transtornos. As inadequações na tradução podem ocorrer devido à interferência da língua fonte na língua alvo, ou vice-versa, gerada pelo contato dos sistemas linguísticos distintos envolvidos. Ter consciência de que no momento da tradução as línguas fonte e alvo estão em relação pode ajudar o tradutor a fazer opções mais adequadas à função elegida para o texto.

Nesse contexto é importante a preocupação com a adequação do texto traduzido à cultura alvo, pois, como afirmam Possamai e Leipnitz (2007, p. 2021), é papel do tradutor fazer o texto alvo chegar a seu público de maneira satisfatória e compreensiva à cultura de destino. Considerando todas essas questões, Azenha (1996, p. 147) sugere um redimensionamento do perfil do tradutor técnico, de seus diferentes papéis como centro do processo decisório e de seu grau de responsabilidade ao se avaliar seu trabalho. Segundo ele, é o tradutor quem precisa conscientizar-se primeiro do seu papel e de sua importância e, como consequência, deve conscientizar seu cliente.

\section{A tradução de textos técnicos na prática}

O objeto de estudo do presente artigo são dois manuais de instrução, a saber: o manual de instruções de uma caixa de som para celulares da Nokia - Nokia Mini Speaker MD-11 - e o manual de instruções de um relógio de pulso da marca Casio. O corpus foi selecionado por apresentar exemplos que ilustram as considerações teóricas apresentadas assim como as reflexões pertinentes à tradução de textos de especialidade que norteiam o presente artigo. As análises foram feitas pelo método comparativo, cotejando o texto fonte com o texto alvo.

Em um primeiro momento, a decisão por investigar as especificidades da tradução de marcas culturais em textos técnicos levou à busca de um corpus que contivesse marcadores culturais. Por isso a escolha de manuais de instruções, cujas traduções, à primeira impressão, podem soar apenas como a reprodução fiel e repetitiva da língua e da cultura fonte transpostas ao público alvo, o que não é verdade, uma vez que para desempenhar seu papel, ou seja, instruir o usuário no manuseio correto dos aparelhos, é extremamente necessário que o manual se mostre culturalmente adequado ao público leitor. 
De acordo com Polchlopek e Aio (2009, p. 105), algumas características comuns aos textos técnicos ou de especialidade são: uso do tempo presente; asserções e frases curtas; pretensão à ausência de ambiguidade; pouca adjetivação; emprego da voz passiva e de modais; parágrafos curtos; dados estatísticos; nominalizações e terminologia técnica. É importante para este trabalho destacar também as características dos textos instrutivos, gênero ao qual os materiais citados pertencem e que apresentam informações técnicas e regras do que deve ou não ser feito. Algumas delas são: linguagem prescritiva, objetiva e enxuta, com uso do imperativo; topicalizações; e frases curtas. Além disso, apresentam imagens para ilustrar e facilitar o manuseio do equipamento, como é exemplo a Figura 1:

\section{Nokia Mini Speaker MD-11}

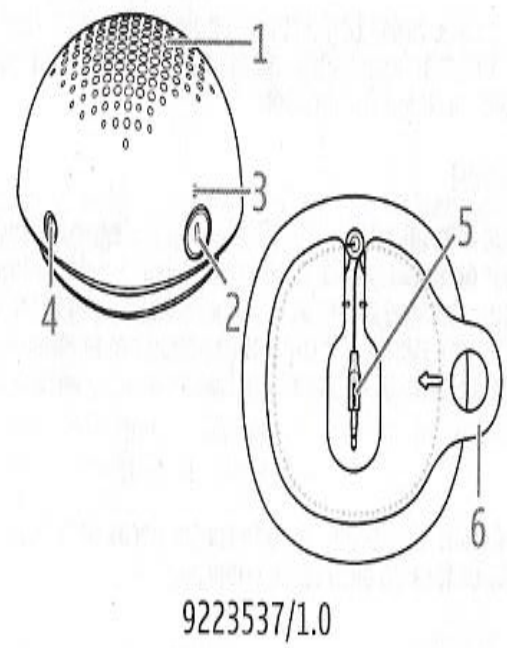

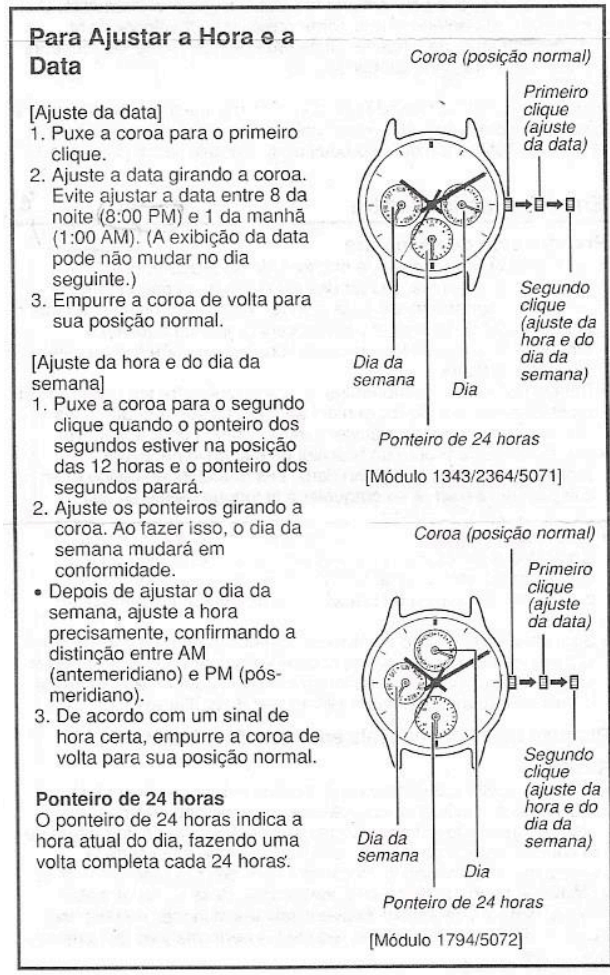

Figura 1 - Imagens dos manuais de instrução indicando os componentes dos seguintes produtos: à esquerda, caixa de som para celular; à direita relógio de pulso.

É importante que o tradutor leve em consideração a função do texto alvo para que possa cumprir seu objetivo. No caso do manual de instruções, a comunicação deve ser estabelecida de maneira eficaz, a fim de evitar riscos à pessoa que manuseia o equipamento e de não proporcionar resultados indesejados. Como afirma Azenha (1996, p. 137):

em se tratando de traduções técnicas, não é pequeno o anedotário sobre os 'desastres' provocados por erros: os casos relatados vão desde acontecimentos mais corriqueiros como eletrodomésticos queimados e motores fundidos, passam por acidentes de maiores proporções como pontes que não se sustentam e chegam a óbitos decorrentes da ingestão em dosagem indevida de medicamentos e até a catástrofes ecológicas provocadas pelo uso incorreto de agrotóxicos. 
No corpus analisado foi possível observar algumas características linguísticas e culturais dos textos fonte, em língua inglesa, assim como escolhas adequadas e outras nem tanto na tradução, em língua portuguesa, que serão descritos a seguir. Essas interferências, sejam para o bem ou para o mal, decorrem, cremos, do contato entre as línguas e as culturas, algo inerente ao ato tradutório.

No caso do manual da caixa de som para celular, aqui chamando de Manual 1, percebemos o uso do imperativo, como normalmente acontece, no texto em inglês. Já na tradução, os verbos aparecem na forma infinitiva, como ilustrado na tabela abaixo:

\begin{tabular}{l|l}
\multicolumn{1}{c|}{ Texto fonte } & \multicolumn{1}{c}{ Texto alvo } \\
\hline insert the batteries & "inserir as baterias" \\
\hline use the speaker & "usar o alto-falante" \\
\hline listen to music & "ouvir música"
\end{tabular}

Esse exemplo ilustra uma das convenções textuais da língua portuguesa: escrever os manuais de instrução usando o modo infinitivo. Por seguir as regras de redação do português do Brasil, torna-se também uma expressão da cultura do país. Ao fazer essa escolha, o tradutor opta por uma tradução que julgamos domesticante, na qual prevalece a cultura-alvo, ou seja, a sua cultura.

Segundo Venuti (1995, p. 18), a domesticação é um procedimento inerente à maior parte dos textos traduzidos, pois se inicia no momento em que se escolhe a obra a ser traduzida e perpassa todas as escolhas tradutórias. Quando se facilita a leitura do texto e a compreensão por parte de seus leitores, elementos pertinentes ao público alvo são inscritos, reescritos, repensados e recriados no texto traduzido com o objetivo de atingir esse fim, caracterizando uma tradução domesticante.

No Manual 1 também foi observada uma inversão na ordem das frases, com o fim de aproximar o texto ao estilo da cultura alvo:

\begin{tabular}{l|l}
$\begin{array}{l}\text { Texto } \\
\text { fonte }\end{array}$ & When the batteries are low on power, a regular beep sounds. \\
\hline $\begin{array}{l}\text { Texto } \\
\text { alvo }\end{array}$ & "Você ouvirá um bipe regular toda vez que a carga das baterias estiver baixa".
\end{tabular}

Inserindo a pessoa (você), o tradutor aproxima o leitor do texto e o torna mais idiomático na língua portuguesa e na cultura brasileira, como também podemos observar no exemplo a seguir, retirado no mesmo manual:

\begin{tabular}{l|l}
$\begin{array}{l}\text { Texto } \\
\text { fonte }\end{array}$ & $\begin{array}{l}\text { When the speaker is not used for long periods remove the batteries to prevent } \\
\text { damage from leakage. }\end{array}$ \\
\hline $\begin{array}{l}\text { Texto } \\
\text { alvo }\end{array}$ & $\begin{array}{l}\text { "Se você não for utilizar o alto-falante por um longo período, remova as baterias } \\
\text { para evitar danos decorrentes de vazamento". }\end{array}$
\end{tabular}

Essa adição foi feita porque endereçar o texto à pessoa é algo comum na cultura brasileira, uma vez que envolve o leitor e o deixa mais atento à leitura. Nesse caso, também chama a atenção para as instruções que seguirão. 
Outras informações importantes foram adicionadas ao manual, tais como o fato de que o site que trata do programa de reciclagem de produtos do grupo Nokia ${ }^{2}$ está em inglês, além da inserção da informação da garantia limitada, que só se encontra no manual traduzido para o português, por questões de leis do direito dos consumidores do Brasil. Essa garantia, que vem como um folheto à parte, é traduzida de maneira diferente, pois é muito mais explicativa, tendo um tamanho mais extenso.

Tal fato demonstra a preocupação dos tradutores e dos representantes da Nokia do Brasil em deixar clara a vigência da lei e dos direitos dos consumidores no país, que é diferente das leis norte-americanas ou de outros lugares, o que mostra a inserção de aspectos da cultura brasileira no texto.

No segundo material analisado, o manual de instruções de um relógio de pulso, aqui chamado de Manual 2, a primeira diferença cultural aparece já na formatação. Conforme as regras da língua inglesa, os títulos apresentam todas as iniciais em letra maiúscula. Já no texto alvo, conforme as regras do português do Brasil, só a inicial da primeira palavra é grafada com letra maiúscula, como demonstrado na tabela a seguir:

\begin{tabular}{l|l}
\multicolumn{1}{c|}{ Texto fonte } & \multicolumn{1}{c}{ Texto alvo } \\
\hline Operating Precaution & "Precauções relativas à operação" \\
\hline Electrostatic Charge & "Carga eletrostática" \\
\hline Resin Components & "Componentes de resina"
\end{tabular}

Outro marcador cultural presente no Manual 2 foi a medida de pressão atmosférica que identifica claramente a qual sociedade/cultura o texto pertence. Na cultura de língua inglesa essa medida é expressa por bar e foi mantida assim no texto alvo, sendo que em português, isto é, na cultura brasileira, o termo científico correto seria "Pa” (Pascal), sua medida de pressão atmosférica padrão.

Nesse caso, o tradutor optou pela estrangeirização - utilizou bar -, ou seja, por trazer a cultura do outro para a sua própria. Segundo Venuti (1995, p. 24):

a noção de estrangeirização pode alterar a maneira como as traduções são lidas, assim como produzidas, porque ela assume um conceito de subjetividade humana que é muito diferente das suposições humanistas que subjazem à domesticação ${ }^{3}$.

Assim, valores culturais do texto fonte são incorporados ao texto alvo e isso permite que o leitor perceba que o texto provém de outra cultura, de outra língua, o que, em tese, segundo Venuti, daria maior visibilidade ao tradutor e ampliaria o conhecimento de mundo do leitor.

Também foram feitas duas adições referentes ao sistema horário, como é possível perceber no exemplo a seguir: "Ajuste a data girando a coroa. Evite ajustar a data entre 8 da noite $(8: 00 P M)$ e 1 da manhã (1:00 $A M)$. A exibição da data pode não mudar no dia seguinte”. As adições - entre parênteses - foram necessárias para facilitar a compreensão do leitor da cultura-alvo, uma vez que este sistema horário ( $A M-$ Ante

\footnotetext{
${ }^{2}$ www.nokia.com/werecycle

${ }^{3}$ Tradução nossa. Texto original: "the notion of foreignization can alter the ways translations are read as well as produced because it assumes a concept of human subjectivity that is very different from the humanist assumptions underlying domestication.”
} 
Meridien e $P M$ - Post Meridien) é pertinente à sociedade e à cultura norte-americanas e não é compartilhado pela sociedade e cultura brasileiras, que utiliza o sistema de 24 horas.

Uma tradução quiçá não adequada foi a da palavra battery por “pilha”, já que muitos chamam a fonte de energia do relógio de pulso de "bateria" e não de "pilha". Outra inadequação foi traduzir os trechos no problem is indicated if the fogging clears up relatively quickly como "não haverá nenhum problema se a condensação desaparecer relativamente logo", e a duty or rusty case can soil the sleeve or clothing causing skin irritation, and even interfere with watch performance como "uma caixa ou pulseira suja ou enferrujada pode manchar a manga da sua roupa, causar a irritação da pele e até interferir com o desempenho do relógio" que em português não soou nada idiomático, já que não falamos "relativamente logo" nem "com o desempenho", mas "relativamente rápido" e "no desempenho". Nesses trechos fica evidente a interferência causada pelo contato das línguas inglesa e portuguesa, que gerou confusão ao tradutor e se refletiu no resultado final.

Esses exemplos de colocações, ou seja, de palavras que combinam ou coocorrem com outras, também ilustram questões culturais, uma vez que só funcionam idiomaticamente e bem juntas dentro de determinada cultura; como vimos, não ficaram adequados os exemplos de tradução literal da língua inglesa para a língua portuguesa do Brasil.

\section{Considerações finais}

Os exemplos retirados dos manuais de instrução da caixa de som para celular e do relógio de pulso embasam o que as reflexões arroladas relatam: que existem marcas linguísticas e culturais em todos os gêneros textuais, mesmo nos técnicos. Como afirma Azenha (1996, p. 142), é possível evidenciar a importância da consideração de aspectos culturais mesmo na tradução de textos técnicos.

É importante, pois, que o tradutor esteja atento a esses marcadores para não correr o risco de incorrer em mal entendidos, e poder situar o texto traduzido o mais próximo da cultura alvo possível, deixando-o, por consequência, mais compreensível e capaz de evitar equívocos.

Consideramos que as questões tradutórias relacionadas à tradução técnica não têm recebido a devida atenção da parte dos estudiosos e faz-se necessário que sejam desenvolvidas análises que "conscientizem” os tradutores, profissionais e iniciantes de que "é necessário abandonar a crença equivocada de que textos técnicos são inferiores aos textos em que a base cultural aparece de forma mais evidente” Azenha (1999, p. 138).

Isso também envolve o despertar da consciência do tradutor para a responsabilidade e as dificuldades aparentemente não presentes no texto técnico, uma vez que: 
a aplicabilidade imediata do que se entende (ou não) a partir da leitura de um texto técnico traduzido sublinha a questão do erro de tradução, ao mesmo tempo em que chama a atenção para a responsabilidade do tradutor e para as possíveis consequências da atividade de traduzir sobre o dia-a-dia das pessoas (AZENHA, 1999, p. 138).

Clara Peron Guedes

claraperonguedes@hotmail.com

Mestranda, Universidade Federal de Pelotas

Isabella Mozzillo

isabellamozzillo@gmail.com

Prof $^{a}$ Dr $^{a}$, Universidade Federal de Pelotas

\section{Referências bibliográficas}

AUBERT, Francis Henrik. Introdução à metodologia de pesquisa terminológica bilíngue. São Paulo: FFLCH/USP, 2001. 103p.

AzENHA JR., João. Tradução técnica e condicionantes culturais: primeiros passos para um estudo integrado. São Paulo: Humanitas, 1999. 157p.

. Tradução técnica, condicionantes culturais e os limites da responsabilidade do tradutor. Cadernos de Tradução, São Paulo, v.1, n.1, p. 137-149, 1996.

Carvalho, Carolina Alfaro de. A tradução para legendas: dos polissistemas à singularidade do tradutor. 2005. 160f. Dissertação (Mestrado em Letras) Programa de Pós-Graduação em Letras, Pontífica Universidade Católica do Rio de Janeiro, Rio de Janeiro.

De Brum, A. Martín. Alguns pressupostos teórico-metodológicos da teoria funcional da tradução: elementos para uma teoria discursiva da tradução. In: Seminário de Estudos em Análise do Discurso, III, Anais. Porto Alegre, 2007, s.p. Disponível em:

$<$ http://www.ufrgs.br/analisedodiscurso/anaisdosead/3SEAD/Comunicacoes/A MartinDeBrum.pdf $>$. Acesso em: 10 out. 2010.

Fanaya, Patrícia Melissa Silva Fonseca. A tradução na era da comunicação interativa: uma releitura do funcionalismo de Nord em interface com a localização. 2009. 103f. Dissertação (Mestrado em Letras) - Programa de PósGradução em Estudos da Tradução, Universidade Federal de Santa Catarina, Florianópolis. 
Gorovitz, Sabine. A tradução como contato de língua. Revista Traduzires, Brasília, v.1, n.2, p. 74-85, 2012.

LEAL, Alice. Funcionalismo e tradução literária: o modelo de Christiane Nord em três contos ingleses contemporâneos. Revista Scientia Traductionis, Florianópolis, n.2, 2006, s.p. Disponível em: $<$ https://periodicos.ufsc.br/index.php/scientia/article/view/12916> Acesso em: 10 out. 2010.

Nord, Christiane. Translating as a Purposeful Activity: Funcionalist Approaches Explained. Michigan: St. Jerome, 1997.154 p.

PolchlopeK, Silvana; Aio, Michele de Abreu. Tradução técnica: armadilhas e desafios. Tradução \& Comunicação - Revista Brasileira de Tradutores, Florianópolis, n.19, p. 101-113, 2009.

Possamai, Viviane; Leipnitz, Luciane. Os estudos de gênero e a tradução: uma relação proveitosa demonstrada por meio da abordagem da tradução de artigos científicos. In: Simpósio Internacional de Estudos de Gêneros, 4. Anais. Tubarão, Santa Catarina: UNISUL, p. 2016-2027. 2007.

RESENDE, Simone Vieira. Normas tradutórias: o caso dos artigos científicos e suas condicionantes culturais. 2011. 139f. Dissertação (Mestrado em Letras) Programa de Pós-Graduação em Letras, Universidade Estadual do Rio de Janeiro, Rio de Janeiro.

Venuti, Lawrence. The Translators Invisibility: A History of Translation. London and New York: Routledge, 1995. 368p. 